\title{
The Cost of Managing Type 2 Diabetes Mellitus in Greece: A Retrospective Analysis of 10-Year Patient Level Data "The HERCULES Study"
}

\author{
Ilias Migdalis, ${ }^{1}$ Grigorios Rombopoulos, ${ }^{2}$ Magdalini Hatzikou, ${ }^{2}$ Christos Manes, ${ }^{3}$ \\ Nikolaos Kypraios, ${ }^{4}$ and Nikolaos Tentolouris ${ }^{5}$ \\ ${ }^{1}$ NIMTS Hospital, 12 Monis Petraki Street, 11521 Athens, Greece \\ ${ }^{2}$ Novartis Hellas, 12th Km National Road 1, Metamorfosis, 14451 Athens, Greece \\ ${ }^{3}$ General Hospital of Thessaloniki "Papageorgiou", West Ring Road, 56429 Thessaloniki, Greece \\ ${ }^{4}$ Polyclinic General Hospital, 3 Peireos Street, 10552 Athens, Greece \\ ${ }^{5}$ Laiko General Hospital, 17 Agiou Thoma Street, 11527 Athens, Greece
}

Correspondence should be addressed to Grigorios Rombopoulos; grigorios.rombopoulos@novartis.com

Received 26 August 2014; Accepted 3 October 2014

Academic Editor: Anastasia Mavrogiannaki

Copyright (C) 2015 Ilias Migdalis et al. This is an open access article distributed under the Creative Commons Attribution License, which permits unrestricted use, distribution, and reproduction in any medium, provided the original work is properly cited.

\begin{abstract}
Objective. This study aimed to estimate the mean annual cost of treating type 2 diabetes mellitus patients (T2DM) including complications and comorbidities in Greece. Design. A noninterventional retrospective study was based on patient level data analysis (bottom-up approach) from medical records, with at least 10-year-follow-up data. Results. The total annual cost per patient for managing diabetes in Greece was estimated at $€ 7,111$ and was, statistically significantly, higher for patients with inadequate glycemic control $(\mathrm{Hbalc}>7 \%)$ versus patients with adequate control (Hbalc $=7 \%)(€ 7,783$ versus $€ 6,366$, resp.; $P=0.017)$. This was mainly attributed to difference in CV hospitalizations between groups 14/111 versus 4/100, respectively, OR = 3.46 (95\% CI: 1.1010.9) for inadequately controlled patients. The largest component of cost was management of comorbidities, accounting for $48 \%$ of costs, and pharmaceutical treatment at $35.9 \%$ while only $14.9 \%$ was attributed to diabetes treatment per se. Obese men and patients with poor education are the groups with higher treatment costs. Conclusions. This is the first study to capture all cost components and the real burden of diabetes in Greece. Comorbidities were found to account for almost half of total cost, significantly higher in nonoptimally controlled diabetes patients.
\end{abstract}

\section{Introduction}

Diabetes mellitus (DM) is a chronic condition primarily defined by the level of hyperglycemia giving rise to risk of microvascular and macrovascular damage $[1,2]$.

Type 2 diabetes mellitus (T2DM) comprises $90 \%$ of people with diabetes around the world and is largely the result of excess body weight and physical inactivity [3]. A recent Greek study in a large representative rural, urban, and suburban population showed that T2DM was associated with advancing age, obesity, exposure to smoke, and low socioeconomic status [4].

T2DM has become an epidemic [5] and affects about 6\% of the adult population in the western world [6]. In Greece, the projected prevalence of T2DM in 2002 was $7.6 \%$ in men and 5.9\% in women [7]. Two other studies estimated the prevalence of diabetes among adult urban and rural populations in Greece: for the urban population it was estimated at $8.2 \%$ (men, 8.5\%; women, $7.8 \%$ ) in 2002 and $9.5 \%$ (men, 9.7\%; women, 9.3\%) in 2006 [8]; for the rural population, the prevalence of diabetes was estimated at $7.8 \%$ in 2002 [9].

There is an increasing trend in the prevalence of diabetes; the study by Wild and colleagues showed that the "diabetes epidemic" will continue even if levels of obesity remain constant [10]. Therefore, this trend becomes even more worrying since the prevalence of obesity, the primary risk factor of T2DM, also exhibits an increasing trend [11, 12]. 
Despite many advances in its treatment over the past few decades, T2DM remains a serious public health problem and is a growing burden on global economies [13]. It is associated with reduced life expectancy; in 2004, an estimated 3.4 million people died from consequences of high fasting blood sugar [14]. The World Health Organization's (WHO) projections show that diabetes will be the 7 th leading cause of death in 2030 [15].

In addition, T2DM is associated with significant morbidity and low quality of life (QoL) due to specific diabetesrelated microvascular complications, increased risk of macrovascular complications (ischemic heart disease, stroke, and peripheral vascular disease), blindness, renal failure, and amputations $[1,16,17]$. According to a recently published Greek study, patients with poorer glycemic control score significantly lower QoL levels compared to their well-controlled counterparts [18].

T2DM is also a very costly disease. The American Diabetes Association (ADA) estimated the total cost of diabetes in the US at $\$ 174$ billion in 2007, including $\$ 116$ billion in excess medical expenditures and $\$ 58$ billion in reduced national productivity [19]. The total direct medical cost of T2DM in eight European countries was estimated at $€ 29$ billion per year (at an average annual cost per patient of $€$ 2,834) [20]. The INSTIGATE study showed that the mean total direct costs per patient in five European countries increased in the 6-month follow-up period, compared with the 6-month period prior to insulin initiation, and ranged from $€ 577$ in Greece to $€ 1402$ in France. In all countries, the breakdown of total direct costs by expenditure category varied considerably across countries, reflecting differences in resource use patterns, prices of medical resources, and different health care systems [21]. In Greece, the annual cost of treating diabetes had been estimated by Athanasakis and colleagues [22]. In addition, a more recent study estimated the mean costs associated with the management of T2DM, after initiating insulin therapy [23]. The aforementioned studies did not include hospitalization, comorbidities, and complications cost.

The primary objective of the study was to estimate the mean annual cost of T2DM treatment in Greece, based on medical records of patients with at least a 10-year history of T2DM. In addition, this study explored the association of total cost of diabetes with $\mathrm{HbAlc}$ levels, after controlling for a set of demographic and socioeconomic parameters, in order to identify the determinants and key cost drivers of diabetes.

\section{Patients and Methodology}

2.1. Description of Study Design. A noninterventional retrospective study was conducted between June 30, 2011, and June 1,2012 , in four diabetes centers operating in public hospitals. The four participating diabetes centers were among the 25 official diabetes centers in Greece and had sufficient databases with a patient follow-up of at least 10 years in order to be able to collect the necessary data retrospectively.

Patients were recruited during their routine visit for the management of their T2DM. Adult T2DM patients receiving any type of antidiabetic treatment at least for 10 years before recruitment who have performed at least one visit per year to the diabetes center throughout the last decade with a complete patient file and adequate medical data according to the evaluation schedule were considered as eligible to participate. Eligibility was assessed by the study investigators, who were medical staff of the aforementioned diabetes centers. Eligible patients willing to participate had to sign an informed consent in order to be enrolled. The study protocol was approved by the Institutional Review Board prior to study initiation (April 2011).

An electronic Case Report Form (eCRF) was developed in order to collect the data necessary for the analysis. The eCRF was completed for each of the patients only once and recorded data, based on patients 10-year medical history and on demographic characteristics, personal information, medical HbAlc measurements, complications of T2DM (all microand macrovascular complications), comorbidities, as well as resource use data (visits to physicians/outpatient visits, frequency and duration of hospitalization, pharmaceutical treatments, and laboratory tests), and work-loss days due to diabetes (absenteeism). Medical history data and laboratory test results were retrieved from medical records. If demographic or nonlaboratory data (absenteeism and number/duration of hospitalizations) were missing, they were collected through direct interviews with the patients conducted by the investigators during the same visit.

According to the study protocol, patients recruited in the study into two subgroups in a predefined $1: 1$ ratio, based on their mean HbAlc level over the last 10 years (at least one $\mathrm{HbAlc}$ measurement per year was a prerequisite). If the average HbAlc was equal or less than 7 , the patient was categorized as adequately controlled, whereas if the average HbAlc was over 7, the patient was categorized as inadequately controlled. In order to achieve the 1:1 ratio, HBAlc measurement was uploaded in the eCRF system upon patient recruitment and participating investigators were informed on the number of patients recruited in each subgroup.

In order to estimate total costs for the management of diabetes and its comorbidities, unit costs were assigned to resource use data collected from patient files and related interviews. Pharmaceutical costs were retrieved from publicly available sources, hospitalization costs from Diagnosis Related Groups (DRGs) tariffs, cost for specialist visits, and examination costs from National Health Care System of Greece (NHS) price list [24-26]. Only direct costs were included in the study. All costs were estimated from the NHS perspective in 2013 prices $(€)$.

2.2. Statistical Analysis. Statistical analysis was conducted with SPSS version 19.0. Descriptive analysis was used to describe the continuous and categorical data of patients. Bivariate and multivariate analyses were conducted to identify the sociodemographic and clinical parameters that mostly influence the cost, at a statistical significance level of 0.05. Bivariate analysis was performed using nonparametric tests (Mann-Whitney and Kruskal-Wallis). Due to the nonnormal distribution of the cost data, all costs were 
TABLE 1: Demographic characteristics.

\begin{tabular}{|c|c|c|c|c|}
\hline & Total $(N=211)$ & HbAlc $\leq 7(N=100)$ & HbAlc $>7(N=111)$ & $P$ value \\
\hline \multicolumn{5}{|l|}{ Age (years) } \\
\hline $\begin{array}{c}\text { Mean } \\
(\mathrm{SD})\end{array}$ & $\begin{array}{l}72.9 \\
(8.1)\end{array}$ & $\begin{array}{l}73.6 \\
(7.5)\end{array}$ & $\begin{array}{l}72.3 \\
(8.6)\end{array}$ & $\mathrm{N} / \mathrm{S}$ \\
\hline \multicolumn{5}{|l|}{ Gender } \\
\hline Males & $106(50.2 \%)$ & $51(51.0 \%)$ & $55(49.5 \%)$ & \multirow{2}{*}{$\mathrm{N} / \mathrm{S}$} \\
\hline Females & $105(49.8 \%)$ & $49(49.0 \%)$ & $56(50.5 \%)$ & \\
\hline \multicolumn{5}{|c|}{ BMI (at time of recruitment) } \\
\hline Normal/thin $(<25)$ & $37(17.5 \%)$ & $26(26.0 \%)$ & $11(9.9 \%)$ & 0.022 \\
\hline Overweight (25-30) & $93(44.1 \%)$ & $43(43.0 \%)$ & $50(45.0 \%)$ & $\mathrm{N} / \mathrm{S}$ \\
\hline Obese $(>30)$ & $81(38.4 \%)$ & $31(31.0 \%)$ & $50(45.0 \%)$ & 0.039 \\
\hline \multicolumn{5}{|l|}{ Years since first diagnosis } \\
\hline $\begin{array}{c}\text { Mean } \\
(\mathrm{SD})\end{array}$ & $\begin{array}{l}21.2 \\
(7.5)\end{array}$ & $\begin{array}{l}20.0 \\
(7.6)\end{array}$ & $\begin{array}{l}22.3 \\
(7.2)\end{array}$ & $\mathrm{N} / \mathrm{S}$ \\
\hline \multicolumn{5}{|l|}{ HbAlc } \\
\hline $\begin{array}{c}\text { Mean } \\
(\mathrm{SD})\end{array}$ & $\begin{array}{c}7.3 \\
(1.0) \\
\end{array}$ & $\begin{array}{c}6.6 \\
(0.4) \\
\end{array}$ & $\begin{array}{c}8.0 \\
(0.8)\end{array}$ & \\
\hline
\end{tabular}

BMI: body mass index; SD: standard deviation.

TABLE 2: Comorbidities.

\begin{tabular}{|c|c|c|c|c|}
\hline & Total $(N=211)$ & HbAlc $\leq 7(N=100)$ & HbAlc $>7(N=111)$ & $P$ value \\
\hline Dyslipidemia & $170 / 211(80.6 \%)$ & $80 / 100(80.0 \%)$ & $90 / 111(81.1 \%)$ & 0.739 \\
\hline Hypertension & $176 / 211(83.4 \%)$ & $78 / 100(78.0 \%)$ & 98/111 (88.3\%) & 0.069 \\
\hline Coronary artery disease & $51 / 211(24.2 \%)$ & $24 / 100(24.0 \%)$ & $27 / 111(24.3 \%)$ & 0.959 \\
\hline Stroke & $15 / 211(7.1 \%)$ & $5 / 100(5.0 \%)$ & 10/111 (9.0\%) & 0.257 \\
\hline Other (not related to T2DM) & $149 / 209(71.3 \%)$ & $71 / 99(71.7 \%)$ & $78 / 110(70.9 \%)$ & 0.897 \\
\hline
\end{tabular}

logarithmically transformed, which allowed for the use of parametric methods and resulted in regression models with better goodness of fit. The variables investigated in the bivariate and multivariate analyses were age, gender, disease control level (HbAlc), body mass index (BMI) at recruitment, comorbidities, and complications.

\section{Results}

3.1. Patient Characteristics. A total of 211 patients were enrolled in the study, of which $100(47.4 \%)$ were categorized as adequately controlled and $111(52.6 \%)$ as inadequately controlled. Patient characteristics were similar in the two subgroups with the exception of BMI and are presented in Table 1. Inadequately controlled patients were more likely to be obese compared to adequately controlled counterparts $(P<0.05)$.

Regarding comorbidities, patients with high HbAlc levels were more likely to suffer from hypertension but the difference was not statistically significant $(88.3 \%$ versus $78.0 \%, P=$ $0.069)$. Moreover, the difference in the prevalence of all other comorbidities between the two groups was not statistically significant (Table 2).
The most common diabetes complications of study population were diabetic retinopathy (37\%) and cardiovascular events (coronary artery disease including myocardial infarction and heart failure) (31\%). Other complications included peripheral vascular disease (18\%), diabetic neuropathy (17\%), renal impairment (10\%), and stroke (8.5\%).

Regarding antidiabetic treatment, patients with high HbAlc levels were on average prescribed more medication than those in the adequately controlled group $(P<0.01)$. The duration of antidiabetic treatment was comparable between the two patient subgroups $(P=0.375)$ (Table 3$)$.

There was a statistically significant difference $(P<0.001)$ in favour of patients on long and short-acting insulin of the adequately controlled group (Table 3 ). Differences in the use of all other antidiabetic agents (alpha-glucosidase inhibitors, biguanides, DPP4 inhibitors, glitazones, GLP-1 analogues, meglitinides, and sulphonylureas) were not statistically significant.

Only $46(21.8 \%)$ of the 211 patients reported that they had been hospitalized during the period under consideration. Patients were on average admitted to hospitals 1.4 times per year for the treatment of diabetes and its complications, with a mean duration of hospitalization of 6.3 days. CV hospitalizations were 3.46 times greater (OR) for inadequately 
TABLE 3: Pharmaceutical treatment: antidiabetic and comorbidities therapies.

\begin{tabular}{|c|c|c|c|c|}
\hline & Total $(N=211)$ & HbAlc $\leq 7(N=100)$ & HbAlc $>7(N=111)$ & $P$ value \\
\hline \multicolumn{5}{|l|}{ Number of antidiabetic agents } \\
\hline $\begin{array}{l}\text { Mean } \\
(\mathrm{SD})\end{array}$ & $\begin{array}{c}3.4 \\
(1.5)\end{array}$ & $\begin{array}{c}3.1 \\
(1.4)\end{array}$ & $\begin{array}{c}3.7 \\
(1.5)\end{array}$ & $<0.01$ \\
\hline \multicolumn{5}{|c|}{ Duration of antidiabetic therapy (years) } \\
\hline $\begin{array}{l}\text { Mean } \\
(\mathrm{SD})\end{array}$ & $\begin{array}{c}7.6 \\
(3.8)\end{array}$ & $\begin{array}{c}7.1 \\
(3.4)\end{array}$ & $\begin{array}{c}8.1 \\
(4.1)\end{array}$ & 0.375 \\
\hline \multicolumn{5}{|l|}{ Number of comorbidities treatments } \\
\hline $\begin{array}{l}\text { Mean } \\
(\mathrm{SD})\end{array}$ & $\begin{array}{c}5.5 \\
(3.0)\end{array}$ & $\begin{array}{c}5.4 \\
(3.2)\end{array}$ & $\begin{array}{l}5.6 \\
(2.8)\end{array}$ & 0.630 \\
\hline \multicolumn{5}{|l|}{ Antidiabetic agents $(n)$} \\
\hline Alpha-glucosidase inhibitors & $22 / 211(10.4 \%)$ & $15 / 111(13.5 \%)$ & $7 / 100(7.0 \%)$ & 0.187 \\
\hline Biguanides & $180 / 211(85.3 \%)$ & $93 / 111(83.8 \%)$ & $87 / 100(87.0 \%)$ & 0.643 \\
\hline DPP4 inhibitors & $59 / 211(28.0 \%)$ & $26 / 111(23.4 \%)$ & $33 / 100(33.0 \%)$ & 0.163 \\
\hline Glitazones & $39 / 211(18.5 \%)$ & $23 / 111(20.7 \%)$ & $16 / 100(16.0 \%)$ & 0.481 \\
\hline GLP-1 analogues & 9/211 (4.3\%) & 4/111 (3.6\%) & $5 / 100(5.0 \%)$ & 0.739 \\
\hline Long-acting insulin & $129 / 211(61.1 \%)$ & $87 / 111(78.4 \%)$ & $42 / 100(42.0 \%)$ & $<0.001$ \\
\hline Rapid-acting insulin & 99/211 (46.9\%) & 68/111 (61.3\%) & $31 / 100(31.0 \%)$ & $<0.001$ \\
\hline Meglitinides & $45 / 211(21.3 \%)$ & 22/111 (19.8\%) & $23 / 100(23.0 \%)$ & 0.693 \\
\hline Sulphonylureas & $137 / 211(64.9 \%)$ & $71 / 111(64.0 \%)$ & $66 / 100(66.0 \%)$ & 0.869 \\
\hline
\end{tabular}

TABLE 4: Resource use associated with hospitalization, complications, and medical care.

\begin{tabular}{|c|c|c|c|c|}
\hline & Total $(N=211)$ & $\mathrm{HbAlc} \leq 7(N=100)$ & HbAlc $>7(N=111)$ & $P$ value \\
\hline \multicolumn{5}{|c|}{ Number of visits to a specialist ${ }^{*}$ per year } \\
\hline $\begin{array}{c}\text { Mean } \\
(\mathrm{SD})\end{array}$ & $\begin{array}{c}3.2 \\
(0.9)\end{array}$ & $\begin{array}{c}3.1 \\
(0.9)\end{array}$ & $\begin{array}{c}3.3 \\
(0.9)\end{array}$ & 0.259 \\
\hline \multicolumn{5}{|c|}{ Number of admissions to hospital per year } \\
\hline $\begin{array}{c}\text { Mean } \\
(\mathrm{SD})\end{array}$ & $\begin{array}{c}1.4 \\
(1.1)\end{array}$ & $\begin{array}{l}1.2 \\
(0.4)\end{array}$ & $\begin{array}{c}1.5 \\
(1.2)\end{array}$ & 0.528 \\
\hline \multicolumn{5}{|c|}{ Duration of hospitalization (days per hospitalization) } \\
\hline $\begin{array}{c}\text { Mean } \\
(\mathrm{SD})\end{array}$ & $\begin{array}{c}6.3 \\
(3.9)\end{array}$ & $\begin{array}{c}6.6 \\
(4.1)\end{array}$ & $\begin{array}{c}6.2 \\
(3.8)\end{array}$ & 0.831 \\
\hline \multicolumn{5}{|c|}{ Number of complications over the last 10 years } \\
\hline $\begin{array}{c}\text { Mean } \\
(\mathrm{SD})\end{array}$ & $\begin{array}{c}2.1 \\
(1.7)\end{array}$ & $\begin{array}{c}2.2 \\
(2.2)\end{array}$ & $\begin{array}{c}2.0 \\
(1.3)\end{array}$ & 0.732 \\
\hline \multicolumn{5}{|c|}{ Duration of complications (years) } \\
\hline $\begin{array}{c}\text { Mean } \\
(\mathrm{SD})\end{array}$ & $\begin{array}{c}6.5 \\
(4.1)\end{array}$ & $\begin{array}{c}5.8 \\
(3.6)\end{array}$ & $\begin{array}{c}6.8 \\
(4.4)\end{array}$ & 0.511 \\
\hline
\end{tabular}

${ }^{*}$ At the diabetes center.

controlled patients (95\% CI: $1.10-10.9)$ versus controlled patients with 14/111 (12.6\%) and 4/100 (4\%), respectively. CV hospitalizations (myocardial infraction, heart failure, bypass, pulmonary edema, angioplasty, and stroke) and difference in stroke incidence between groups justify the total cost difference of controlled and uncontrolled patients. The total number and duration of hospitalizations were comparable between the two subgroups, with small differences not being statistically significant (Table 4).

Number of visits to a specialist in the diabetes center was on average 32.2 over the last 10 years, with no statistically significant differences between the two subgroups $(P=$ 0.259). Although CV hospitalizations and stroke incidence were different between subgroups still the total number and duration of complications due to diabetes were not statistically significantly different between the two groups.

3.2. Costs. The total annual cost per patient for managing diabetes was estimated at $€ 7,111$ ( $S D=4,323)$ excluding disability pensions. The largest component of this cost was management of comorbidities, accounting for $48 \%$ ( $€ 3,353)$ 


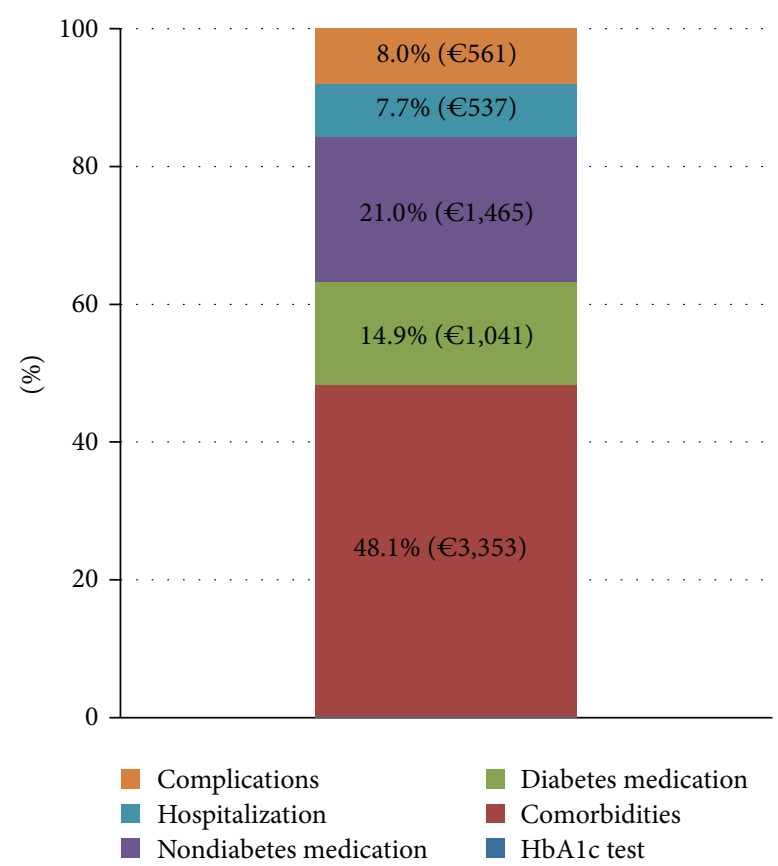

FigURE 1: Breakdown of the total cost of diabetes management. Note: cost of HbAlc test is $0.2 \%$ ( $€ 13$ ) of total cost; disability pensions are excluded.

of total costs, while pharmaceutical treatment (including diabetes-related and nondiabetes medication) accounted for $35.9 \%$ ( $€ 2,506)$. Antidiabetic agents accounted only for $14.9 \%$ ( $€ 1,041)$ of total cost (Figure 1).

For adequately controlled patients, the total cost per year was estimated at $€ 6,366$, while the cost of inadequately controlled patients was estimated at $€ 7,783$, with their difference being statistically significant $(P=0.017)$. Differences in costs of hospitalization and complications between the two subgroups were not statistically significant $(P=0.091)$. Figure 2 presents the breakdown of adequately versus inadequately controlled patients' costs.

Bivariate analyses showed that inadequately controlled patients cost is on average $€ 1,417$ more per year compared to the optimally controlled group $(P=0.017)$. Male patients showed higher costs than females (Table 5); the same applies to overweight or obese patients compared to normal weight. In addition, there was no statistically significant difference found between patient subgroups relating to employment, marital status, and monthly income level.

Existence of comorbidities vastly increases annual costs $(P<0.01)$. In particular, diabetes patients with coronary artery disease (CAD) were found to have the highest yearly cost $(€ 11,662)$, followed closely by those with stroke ( $€$ $11,366)$.

The relationship between the total cost of managing diabetes, the patient characteristics (demographics, personal information, and income level), and T2DM control level was explored through a multivariate analysis, with cost as a dependent variable and all other parameters as explanatory variables. The results of this analysis showed that healthcare

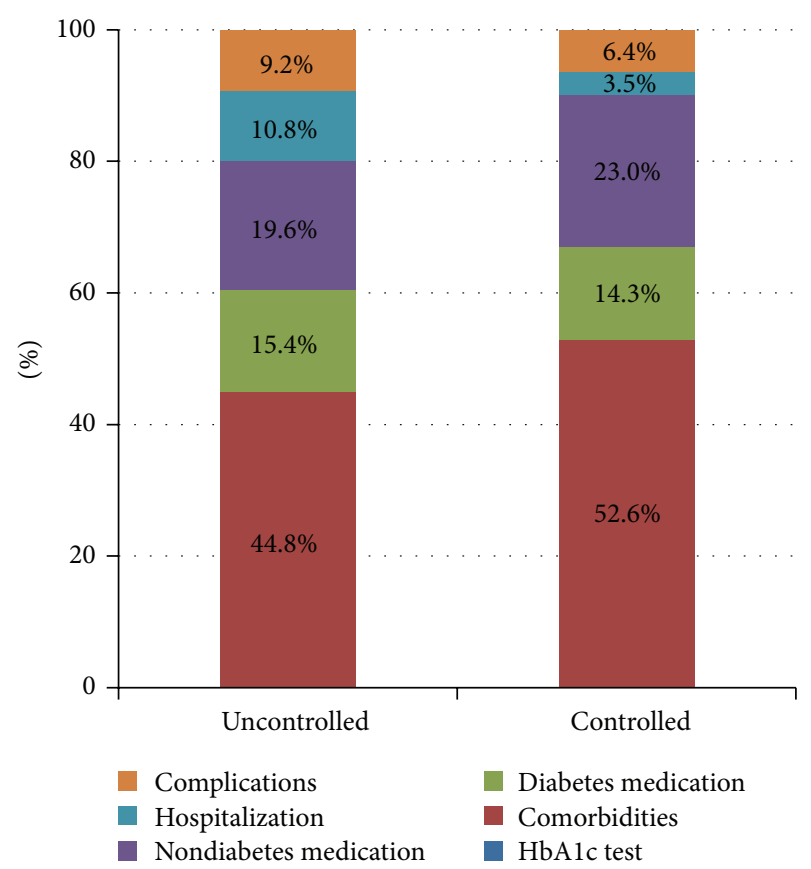

FIGURE 2: Breakdown of total cost of adequately versus inadequately controlled patients. Note: cost of HbAlc test is $0.2 \%$ of total cost in both subgroups; disability pensions are excluded.

for men with diabetes costs $€ 1,277$ more per year, in comparison to healthcare for women with diabetes, and also that treating obese diabetics costs $€ 1,460$ more per year in comparison to treating patients in other BMI groups. In addition, low education level (up to primary school) patients with diabetes cost $€ 2,341$ more on average in comparison to better educated patients, while adding a year in the diabetes history of a patient increases his/her annual cost by almost $€ 90$.

\section{Discussion}

The current study aimed to estimate the total cost of T2DM in Greece, based on a dataset of patients being followed up for at least 10 years. The main finding is that the average annual cost of diabetes treatment was $€ 7,111$. The estimates of the total cost of diabetes are much higher than those reported by previous Greek studies. In particular, Athanasakis and colleagues estimated the annual per patient cost at $€ 1,297$ per patient ranging from $€ 982$ to $€ 1,566$ for adequately controlled and inadequately controlled patients, respectively [22]. However, the latter study included only treatment cost and not costs of diabetic complications and comorbidities which, combined, are the largest component of the total cost (56\%), as shown in the present study. For similar reasons, the current results deviate from the cost estimates of the study of Aloumanis et al., presenting a range between $€ 496$ before initiation of insulin treatment and $€ 573$ after initiating insulin therapy [23].

The current findings are in accordance with estimates of other international studies, which also show high per patient costs for the management of diabetes. In particular, the 
TABLE 5: Average annual costs by patient subgroups.

\begin{tabular}{|c|c|c|c|}
\hline & $\begin{array}{c}\text { Mean annual } \\
\text { cost per } \\
\text { patient }\end{array}$ & SD & $P$ value \\
\hline \multicolumn{4}{|l|}{ HbAlc } \\
\hline HbAlc $>7$ & $7,783.3$ & $4,549.0$ & \multirow{2}{*}{0.017} \\
\hline $\mathrm{HbAlc} \leq 7$ & $6,366.6$ & $3,948.7$ & \\
\hline \multicolumn{4}{|l|}{ Gender } \\
\hline Women & $6,470.5$ & $2,677.0$ & \multirow{2}{*}{0.037} \\
\hline Men & $7,747.2$ & $5,428.5$ & \\
\hline \multicolumn{4}{|l|}{ BMI } \\
\hline Normal/thin $(<25)$ & $5,837.7$ & $3,911.9$ & $\begin{array}{c}<0.01 \\
\text { (versus } \\
\text { obese) }\end{array}$ \\
\hline Overweight (25-30) & $6,903.8$ & $4,491.2$ & $\begin{array}{c}<0.01 \\
\text { (versus } \\
\text { obese) }\end{array}$ \\
\hline Obese $(>30)$ & $7,932.8$ & $4,183.6$ & - \\
\hline \multicolumn{4}{|l|}{ Education } \\
\hline Primary school & $8,104.2$ & $4,649.9$ & - \\
\hline Secondary school & $5,640.2$ & $2,575.1$ & $\begin{array}{c}<0.01 \\
\text { (versus } \\
\text { primary) }\end{array}$ \\
\hline High school & $6,817.1$ & $3,885.2$ & $\begin{array}{c}<0.01 \\
\text { (versus } \\
\text { primary) }\end{array}$ \\
\hline University & $6,405.9$ & $4,731.1$ & $\begin{array}{c}<0.01 \\
\text { (versus } \\
\text { primary) }\end{array}$ \\
\hline \multicolumn{4}{|l|}{ Comorbidities } \\
\hline Dyslipidemia & $7,889.6$ & $4,290.1$ & $\begin{array}{c}<0.01 \\
(\text { versus CAD) }\end{array}$ \\
\hline Hypertension & $7,847.0$ & $4,257.3$ & $\begin{array}{c}<0.01 \\
(\text { versus CAD) }\end{array}$ \\
\hline Coronary artery & $11,662.4$ & $5,592.9$ & - \\
\hline Stroke & $11,366.4$ & $8,389.2$ & $\begin{array}{c}<0.01 \\
(\text { versus CAD) }\end{array}$ \\
\hline Other & $7,699.8$ & $4,349.3$ & $\begin{array}{c}<0.01 \\
\text { (versus CAD) }\end{array}$ \\
\hline
\end{tabular}

BMI: body mass index; CAD: coronary artery disease.

American Diabetes Association study estimated that people with diagnosed diabetes incur average medical expenditures of about $\$ 13,700$ per year, of which about $\$ 7,900$ is attributed to diabetes [27]. In addition, $23 \%$ of the medical costs are used to directly treat diabetes, while $50 \%$ of the costs are used to treat the portion of chronic complications that are attributed to diabetes [19]. This is comparable to our finding that treating comorbidities accounts for $48 \%$ of total costs.

The present study is the first one in Greece to have captured most of the cost components and therefore it may more accurately reflect the real burden of diabetes in the Greek health care setting. Estimating indirect costs were beyond the scope of this study; however, if indirect cost was included, estimates of total costs of T2DM would have been even higher.

The study also showed that the cost of treating inadequately controlled patients was statistically significantly higher $(€ 7,783)$ than the cost associated with treating adequately controlled patients $(€ 6,366)$, a finding which is also consistent with the literature [22]. From a recent published Greek study performed on 6,631 T2DM patients, the majority of the sample (59\%) was inadequately controlled, leading to an additional burden of the national health care budget [18]. Another interesting finding of this study is that, concerning the cost of treatment, with the exception of the insulin, no statistically significant difference was observed between the two groups. This could be attributed to the legacy effect due to limited treatment options during the first decade of the diabetes history of study sample (mean T2DM duration about 20 years in the study population).

The current study had several limitations, one of which is the 10-year retrieval of data which might be underreported in patients file. Additionally, recall bias of such a long period might also be considered as a limitation. Based on the abovementioned, the lack of statistical significance in hospitalization and absenteeism between the two subgroups (adequately and inadequately controlled) could be partly attributed to recall bias arising from the fact that data on hospitalization were retrieved through interviews. The same applies to complication costs as that could be attributed to the retrospective design of the study. However, the abovementioned limitations could be considered as symmetric across the two subgroups and therefore of minimal effect.

\section{Conclusions}

This study is the first aiming to capture all cost components and better reflect the real burden of diabetes in the Greek setting. The cost of managing diabetes in Greece is high and is statistically significantly higher for inadequately controlled versus adequately controlled patients, attributed mainly to difference in $\mathrm{CV}$ hospitalizations and numbers of stroke. Obese men with a long diabetes history and patients with lower educational levels are the subgroups found to have higher treatment cost. The management of comorbidities constitutes a major cost component, accounting for $48 \%$ of total costs, while T2DM-related pharmaceutical treatment accounted only for $14.9 \%$. Since comorbidities account for almost half of diabetes expenditure and inadequately controlled patients have significantly higher costs than adequately controlled, any efforts to contain diabetes burden should be aiming at preventing complications and comorbidities in order to reduce costs of managing diabetes.

\section{Conflict of Interests}

G. Rombopoulos and M. Hatzikou are Novartis Hellas employees, I. Migdalis, C. Manes, N. Kypraios, and N. Tentolouris received compensation as trial investigators from Novartis Hellas. 


\section{References}

[1] World Health Organization, "Definition and diagnosis of diabetes mellitus and intermediate hyperglycaemia," 2006.

[2] World Health Organization, Diabetes: Fact sheet No 312, 2013, http://www. who.int/mediacentre/factsheets/fs312/en/index. html.

[3] World Health Organization, Definition, Diagnosis and Classification of Diabetes Mellitus and Its Complications. Part 1: Diagnosis and Classification of Diabetes Mellitus, World Health Organization, Geneva, Switzerland, 1999.

[4] N. Tentolouris, A. Andrianakos, G. Karanikolas et al., "Type 2 diabetes mellitus is associated with obesity, smoking and low socioeconomic status in large and representative samples of rural, urban, and suburban adult Greek populations," Hormones, vol. 11, no. 4, pp. 458-467, 2012.

[5] M. Stumvoll, B. J. Goldstein, and T. W. van Haeften, “Type 2 diabetes: principles of pathogenesis and therapy," The Lancet, vol. 365, no. 9467, pp. 1333-1346, 2005.

[6] H. King, R. E. Aubert, and W. H. Herman, "Global burden of diabetes, 1995-2025: prevalence, numerical estimates, and projections," Diabetes Care, vol. 21, no. 9, pp. 1414-1431, 1998.

[7] D. B. Panagiotakos, C. Pitsavost, C. Chrysohoout, and C. Stefanadis, "The epidemiology of type 2 diabetes mellitus in Greek adults: the ATTICA study," Diabetic Medicine, vol. 22, no. 11, pp. 1581-1588, 2005.

[8] A. Gikas, A. Sotiropoulos, D. Panagiotakos et al., "Rising prevalence of diabetes among Greek adults: findings from two consecutive surveys in the same target population," Diabetes Research and Clinical Practice, vol. 79, no. 2, pp. 325-329, 2008.

[9] A. M. Melidonis, S. M. Tournis, M. K. Kompoti et al., "Increased prevalence of diabetes mellitus in a rural Greek population," Rural and Remote Health, vol. 6, no. 1, p. 534, 2006.

[10] S. Wild, G. Roglic, A. Green, R. Sicree, and H. King, "Global prevalence of diabetes: estimates for the year 2000 and projections for 2030," Diabetes Care, vol. 27, no. 5, pp. 1047-1053, 2004.

[11] World Health Organization, Obesity 1998: Preventing and Managing the Global Epidemic, World Health Organization, Geneva, Switzerland, 1998.

[12] C. L. Ogden, M. D. Carroll, L. R. Curtin, M. A. McDowell, C. J. Tabak, and K. M. Flegal, "Prevalence of overweight and obesity in the United States, 1999-2004," The Journal of the American Medical Association, vol. 295, no. 13, pp. 1549-1555, 2006.

[13] The International Diabetes Federation. IDF Diabetes Atlas, 2009.

[14] World Health Organization, Global Health Risks. Mortality and Burden of Disease Attributable to Selected Major Risks, World Health Organization, Geneva, Switzerland, 2009.

[15] World Health Organization, Global Status Report on Noncommunicable Diseases 2010, 2011.

[16] P. Hogan, T. Dall, and P. Nikolov, "Economic costs of diabetes in the US in 2002," Diabetes Care, vol. 26, pp. 917-932, 2003.

[17] P. Zimmet, K. G. M. M. Alberti, and J. Shaw, "Global and societal implications of the diabetes epidemic," Nature, vol. 414, no. 6865, pp. 782-787, 2001.

[18] G. Rombopoulos, M. Hatzikou, D. Latsou, and J. Yfantopoulos, "The prevalence of hypoglycemia and its impact on the quality of life (QoL) of type 2 diabetes mellitus patients (The HYPO Study)," Hormones, vol. 12, no. 4, pp. 550-558, 2013.
[19] American Diabetes Association, "Economic costs of diabetes in the U.S. In 2007," Diabetes Care, vol. 31, no. 3, pp. 596-615, 2008.

[20] B. Jönsson, "Revealing the cost of Type II diabetes in Europe," Diabetologia, vol. 45, no. 6, pp. S5-S12, 2002.

[21] S. Jones, C. Castell, A. Goday et al., "Increase in direct diabetesrelated costs and resource use in the 6 months following initiation of insulin in patients with type 2 diabetes in five European countries: data from the INSTIGATE study," ClinicoEconomics and Outcomes Research, vol. 4, no. 1, pp. 383-393, 2012.

[22] K. Athanasakis, M. Ollandezos, A. Angeli, A. Gregoriou, M. Geitona, and J. Kyriopoulos, "Estimating the direct cost of type 2 diabetes in Greece: the effects of blood glucose regulation on patient cost," Diabetic Medicine, vol. 27, no. 6, pp. 679-684, 2010.

[23] K. Aloumanis, M. Benroubi, S. Sourmeli, and V. Drossinos, "Clinical outcomes and costs for patients with type 2 diabetes mellitus initiating insulin therapy in Greece: two-year experience from the INSTIGATE study," Primary Care Diabetes, vol. 7, no. 3, pp. 235-242, 2013.

[24] Greek Ministry of Health, Drug Price Bulletin 05/06/13, 2014, http://www.moh.gov.gr/.

[25] Greek Ministry of Health, Diagnosis Related Groups March, 2012, http://www.moh.gov.gr/articles/health/domes-kai-draseis-gia-thn-ygeia/kwdikopoihseis/709-kleista-enopoihmenanoshlia-1.

[26] FEK 157/91 issue A, http://www.et.gr/index.php.

[27] American Diabetes Association, Economic Costs of Diabetes in the U.S. in 2012. Diabetes Care, American Diabetes Association, Alexandria, Va, USA, 2013. 


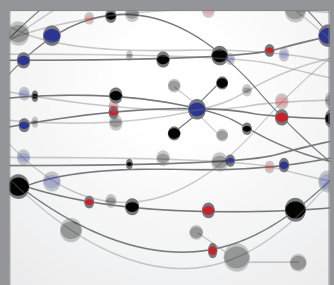

The Scientific World Journal
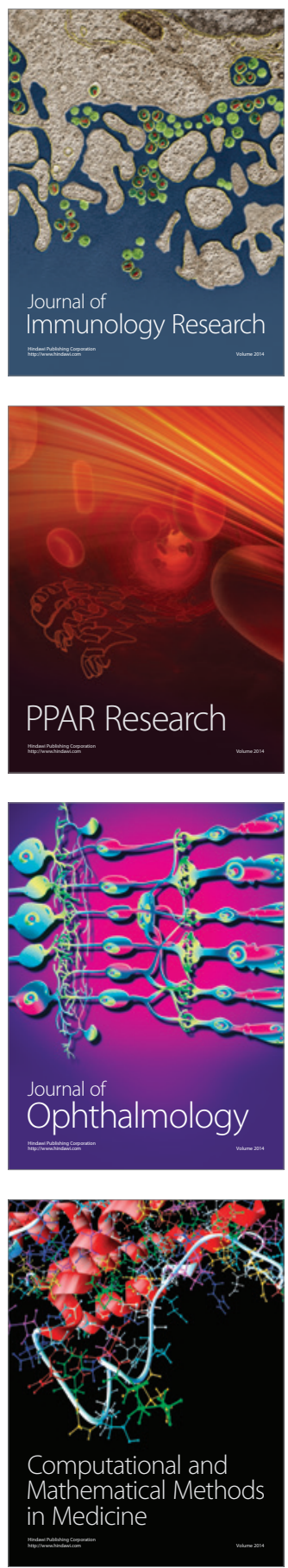

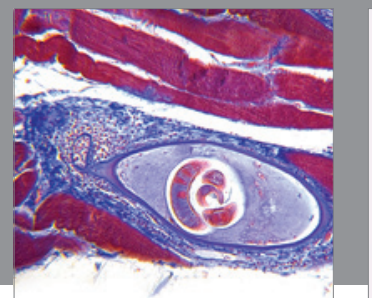

Gastroenterology

Research and Practice
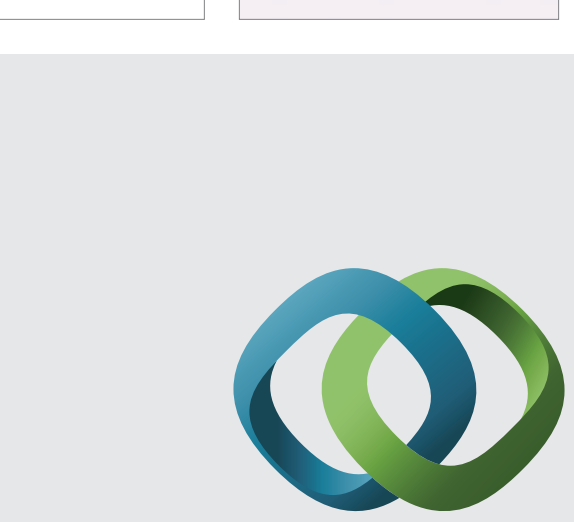

\section{Hindawi}

Submit your manuscripts at

http://www.hindawi.com
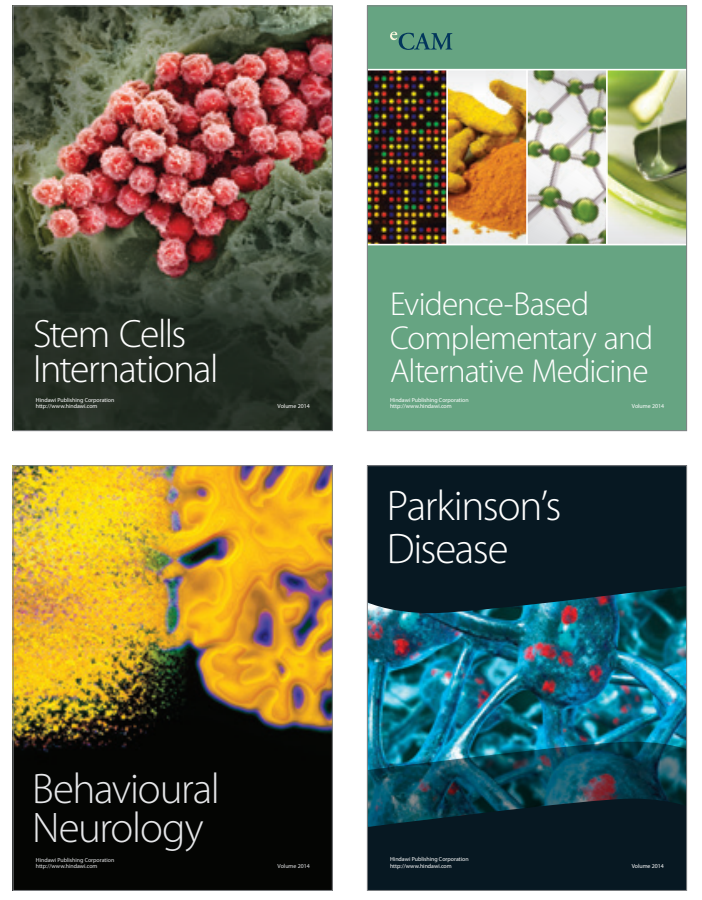
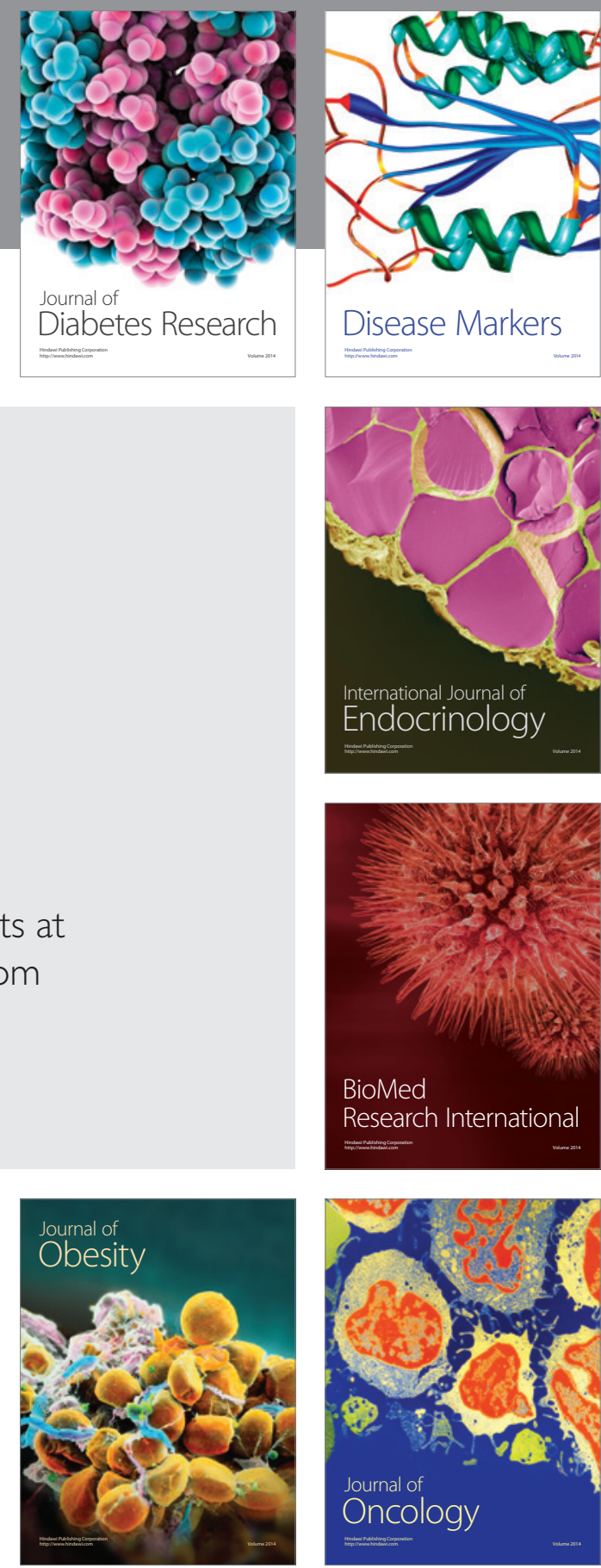

Disease Markers
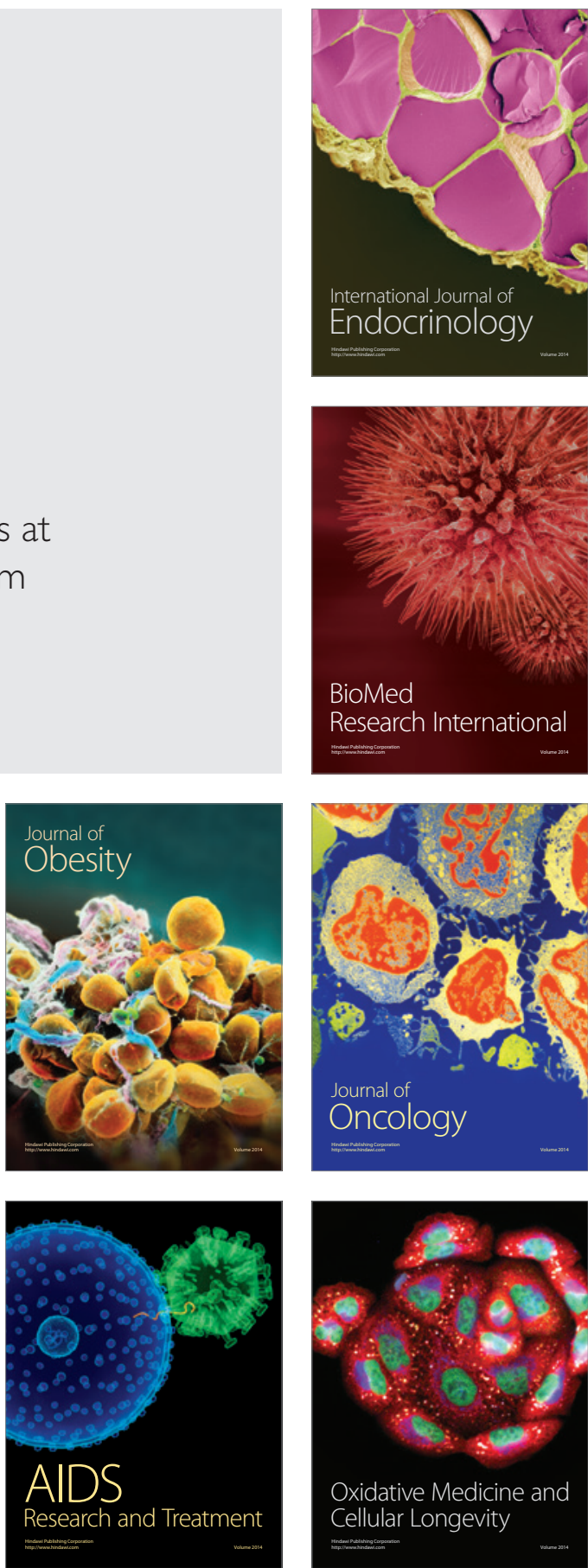